\title{
ETIOLOGIA E PROGRESSO DA MANCHA DE PESTALOTIA DO COQUEIRO (Cocos nucifera L.), EM SÃO GONÇALO, PARAÍBA ${ }^{1}$
}

\author{
GLEIBSON DIONÍZIO CARDOSO ${ }^{2}$, ARTUR FRANCO BARRETO ${ }^{3}$, EGBERTO ARAÚJO ${ }^{4}$, FERNANDES ANTONIO DE \\ ALMEIDA $^{5}$, RENATO AUGUSTO GOUVEIA DE CARVALHO ${ }^{6}$
}

\begin{abstract}
RESUMO - A cultura do coqueiro vem se expandindo no estado da Paraíba, destacando-se a microrregião do Alto Piranhas. O objetivo do trabalho foi determinar a etiologia e caracterizar o progresso de uma doença foliar do coqueiro híbrido. As observações concernentes ao progresso da doença foram realizadas mensalmente, sendo determinadas incidência, severidade e taxas de infecção. Um fungo do gênero Pestalotiopsis (Pestalotia) foi isolado, sendo comprovada a sua patogenicidade. As incidências da doença, em todas as avaliações, corresponderam a $100 \%$. No progresso da severidade da doença, as taxas de infecção foram negativas, sendo os valores da severidade mais elevados quando se verificou a ocorrência de microácaro e cochonilha.
\end{abstract}

Termo de indexação: doença, epidemiologia, coco, coqueiro.

\section{ETHIOLOGY AND PROGRESS OF THE PESTAlOTIOPSIS LEAF SPOT IN COCONUT (Cocos nucifera L.) PLAN- TATIONS AT THE DISTRICT OF SÃo GONÇALO, SOUSA, PARAÍBA STATE}

\begin{abstract}
The coconut has been spreading out in Paraíba State, mainly in Alto Piranhas microrregion, which yield besides supplying the regional market it is being exported to the South and Southeast regions of Brasil. The aim of this research was to determine the ethyology and the progress of a coconut hibrid foliar disease observed in the district of São Gonçalo, Sousa, Paraíba State. The studies concerning to the disease ethiology were carried out into laboratory and greenhouse. Epiphytiologic observations related to the disease progress in the coconut plantations were made monthly in order to determine the incidence, severity and infection rates. A fungus of the Pestalotiopsis (Pestalotia) genera was isolated and developed disease symptoms when was inoculated in wounded coconut leaves. The symptoms presented by the leaves either naturally and artificially infected were similars to those described in the literature for the coconut leaf spot caused by Pestalotiopsis guepinii. The incidence in all evaluations were equal to $100 \%$. It was obtained negative infection rates for severity. The higher values of severity occurred associated to the presence of mites and coccidies in the plants.
\end{abstract}

Index Terms: disease, epidemic, coconut fruit.

No Nordeste foram constatadas doenças fúngicas (Pontes, 1996; Ferreira et al. 1998), micoplasmoses (Chiachio et al. 1997) e o anel vermelho causado pelo nematóide Bursaphelenchus cocophilus (Ferreira et al. 1998). O conhecimento das doenças nas regiões produtoras determina a adoção de medidas racionais de controle. Nesse contexto, o presente trabalho foi realizado com os objetivos de determinar a patogenicidade de um fungo do gênero Pestalotia (Pestalotiopsis), observado com frequiência associado às lesões, bem como observar o progresso dessa doença em áreas de plantio de coqueiro híbrido daquele distrito.

A primeira fase deste trabalho consistiu na coleta de folhas infectadas, realizada no Distrito de São Gonçalo, Paraíba. Observou-se em folhas de coqueiro híbrido manchas elípticas escuras entre 1 e $5 \mathrm{~mm}$ de comprimento e lesões irregulares de coloração parda - escura, de tamanhos variados, resultantes da confluência das lesões menores.

Para isolamento do patógeno, lavou-se parte das folhas coletadas em água corrente, em seguida foram retirados fragmentos ( $3 \mathrm{~mm})$ das partes lesionadas, que foram postos durante um minuto em solução de hipoclorito de sódio a $1 \%$, contido em placa de Petri; depois foram lavadas com álcool etílico 95\% e água destilada esterilizada, por cinco minutos. Em seguida, em tubos de ensaio contendo meio de cultura de BDA, foram colocados três fragmentos. A incubação foi feita em ambiente natural (sem controle de iluminação e temperatura) e em uma câmara com regime de iluminação, proporcionada por lâmpada N.V.V (próximo ao ultravioleta) e fotoperíodo de 12 horas. Os testes de patogenicidade foram realizados utilizando-se suspensões de esporos obtidas de colônias com idade de 15 dias após o plantio em meio de cultura. Em laboratório os segmentos de folhas sadias de mudas e de plantas adultas de coqueiro híbrido, após desinfestados durante um minuto em solução de hipoclorito de sódio a $1 \%$ e lavados em água estéril foram colocados sobre papel de filtro umedecido contido em placas de Petri. Suspensão de esporos na concentração de $10^{3}$ e água estéril (controle) foram derramadas sobre os segmentos foliares com ferimentos (por meio de puncturas com estilete) e sem ferimentos. A inoculação em casa de vegetação foi realizada em mudas de coqueiro híbrido (de 60 dias) desenvolvidas em substrato (solo) contido em sacos de polietileno, sendo as suas folhas desinfestadas como as anteriores. Em seguida realizou-se a aplicação da suspensão de esporos e da água estéril sobre as folhas previamente feridas por meio de estilete, e sobre folhas não feridas, sendo todas elas envoltas durante 72 horas por um saco plástico que se constituiu na câmara úmida.

Os estudos epifitiológicos foram realizados entre junho de 1999 a junho de 2000, nas plantações onde se coletou o material para o diagnóstico da doença. Em cada campo de produção, visitado mensalmente, foram selecionadas, aleatoriamente, dez plantas; nestas, também aleatoriamente, foram cortados dez folíolos de uma de suas folhas. O material coletado foi avaliado, comparando-se o observado a uma escala de notas: 0 - folha sadia; 1 - manchas elípticas, de 1 a $3 \mathrm{~mm}$ de comprimento, de coloração preta, distribuídas espaçadamente no folíolo verde; 2 - manchas elípticas, de 1 a $3 \mathrm{~mm}$ de comprimento, mais numerosas, de coloração preta, com o folíolo apresentando secamento nas áreas de distribuição das manchas; 3 - manchas maiores de $3 \mathrm{~mm}$ de comprimento, algumas coalescentes, observando-se a ampliação da área ressequida do folíolo; 4 - manchas distribuídas como na nota anterior, porém com ampliação da área ressequida e, 5 - manchas iguais ao anterior, porém o folíolo totalmente ressequido. Após a leitura das notas determinou-se a severidade (S) da doença empregando-se o Índice de Mackiney (Chester, 1950).

Os dados de severidade obtidos foram comparados às datas de observação para caracterização das curvas de progresso. Também foi determinada a taxa de infecção r, segundo Van Der Plank (1963), sendo que para isso, os dados obtidos em percentagens ( $\mathrm{x}$ ) foram transformados em $\ln$ x/100-x e plotados no tempo (dias de observação), visando obter a equação de regressão linear. $\mathrm{O}$ coeficiente de regressão correspondeu à taxa de infecção dos períodos (meses) analisados.

Os sintomas da doença estudada, em condições naturais de infecção, consistiram de lesões arredondadas elípticas de bordas defini-

\footnotetext{
${ }^{1}$ (Trabalho 014/2003). Recebido: 23/12/2002. Aceito para publicação: 18/06/2003.

${ }^{2} \mathrm{Eng}^{\circ} \mathrm{Agr}^{\circ}$ Mestrando em Agronomia (UFPB/CCA, Areia), Vila Acadêmica, 58397-000. e-mail: gleibson75@ hotmail.com.

${ }^{3}$ Eng $^{\circ}$ Agr $^{\circ}$ Mestrando em Agronomia (UFPB/CCA, Areia), Vila Acadêmica, 58397-000. e-mail: arturfrancbarr@ bol.com.br.

${ }^{4}$ Professo Adjunto do Departamento de Fitotecnia- CCA/UFPB, Areia-PB. 58397-000.

${ }^{5}$ M.Sc. em Produção Vegetal (UFPB/CCA, Areia), Vila Acadêmica, 58397-000, Areia, PB, e-mail: agrof@ bol.com.br.

${ }^{6} \mathrm{Eng}^{\mathrm{O}} \mathrm{Agr}^{\mathrm{0}}$ (UFPB/CCA, Areia). Vila Acadêmica, 58.397-000.
} 
das, com coloração escura e tamanho entre 3 e 5 mm. Com a expansão e confluência das lesões verificaram-se descolorações pardas avermelhadas e, posteriormente, o secamento das áreas das raquis que envolviam as lesões. O fungo isolado das lesões naturais apresentou estruturas reprodutivas (conídios) semelhantes às do gênero Pestalotiopsis. Nas folhas inoculadas artificialmente, os sintomas, menos intensos, foram semelhantes aos das infecções naturais. Os sintomas observados nas infecções naturais e no material inoculado artificialmente, assemelharam-se àqueles descritos por Anjos et al. (2000), para a mancha foliar causada por Pestalotiopsis guepinii (Desm.) Steyaert. Os mesmos autores observaram a doença ocorrendo em mudas de coqueiro, porém, no presente trabalho, em condições de campo, a doença foi verificada em plantas que já estavam produzindo frutos. No teste de patogenicidade foram observadas lesões em folhas de mudas de coqueiro e de plantas adultas, porém isso se verificou apenas naquelas que foram feridas por ocasião da inoculação. As diversas espécies de fungos do gênero Pestalotiopsis (Pestalotia) que afetam as plantas da família Palmaceae são considerados patógenos fracos (infectam áreas previamente feridas) e ocorrem associados a outros patógenos (Ram, 1989) ou a insetos (Araújo et al., 1991).

Constatou-se em campo, que todas as raquis estavam afetadas, verificando-se, portanto, uma incidência de $100 \%$ da doença. O progresso da doença foi caracterizado pela severidade (Figura 1A). Para essa variável, os maiores valores foram encontrados nas primeiras avaliações e estes decresceram continuamente até o mês de dezembro de 1999, obtendo-se, no período, uma taxa de infecção negativa (Figura 2A). Observa-se na Figura 1B que, entre os meses de junho a setembro de 1999, as quantidades de chuvas que se registraram foram mínimas $(\geq 5 \mathrm{~mm})$ ou nulas $(0 \mathrm{~mm})$. Os

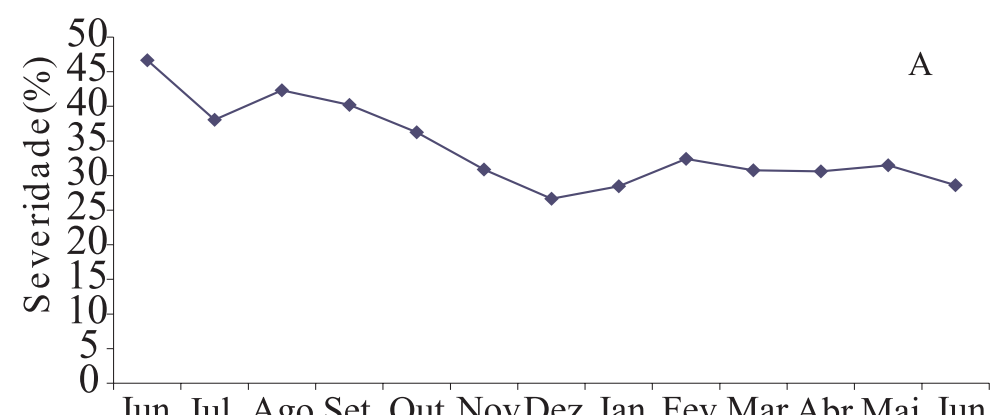

FIGURA 1 - Severidade da doença - A e precipitação pluviométrica mensal - B, durante o período de observação. Distrito de São Gonçalo, Sousa - PB, 1999-2000.
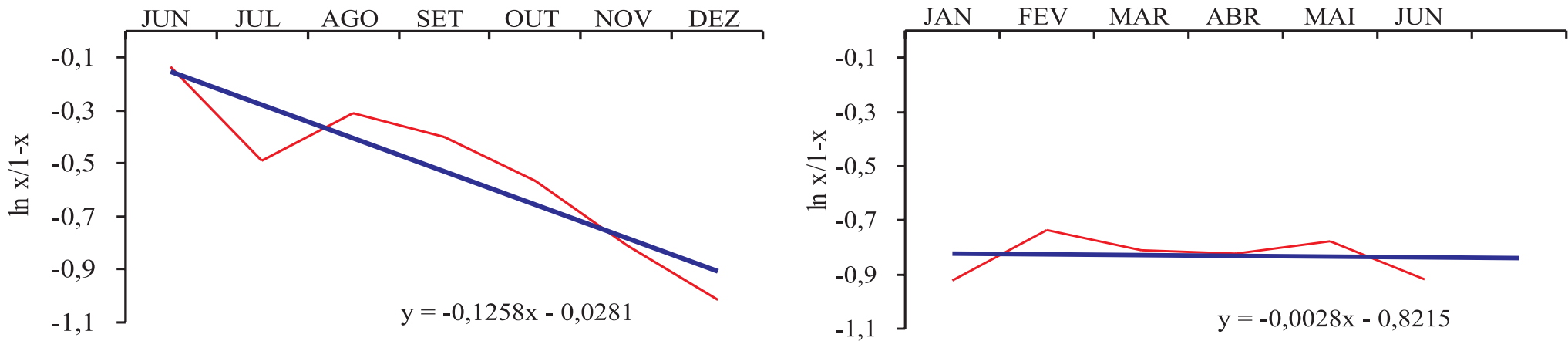

FIGURA 2 - Evolução da Severidade da doença no período de junho a dezembro de 1999 - A e de janeiro à junho de 2000 - B (dados transformados em $\ln \mathrm{x} / 1-\mathrm{x}$ ) da mancha da Pestalotiopsis sp em coqueiro, no Distrito de São Gonçalo, Paraíba. Os coeficientes de regressão $b_{1}=-0,1258$ e $b_{2}$ $=-0,0028$ correspondem à taxa de infecção $\mathbf{r}$.

\section{REFERÊNCIASBIBLIOGRÁFICAS}

ANJOS, J.R.N.; MARIA, J.A.; CHACHAR; VICTOR, H.V. RAMOS; Mancha foliar causada por Pestalotiopsis guepinii. em coqueiro no Distrito Federal. Fitopatologia Brasileira, Brasília, v. 25, p. 121-215, 2000.

ARAÚJO, J.C.A. de GASPAROTTO, L; GARCIA, M.V.B. Epidemiologia de Pestalotiopsis spp em dendenzeiro. Fitopatologia Brasileira, Brasília, v. 16, n. 2, p.33. Jun.,1991.

CHESTER, K.S. Plant disease losses: their appraisal and interpretatio. Plant Disease Report, St. Paul, v. 193, Suplement, p.190-362. 1950.

CHIACCHIO, F.P.B., SANTOS FILHO, H.P., OLIVEIRA. O.P., ALMEIDA,

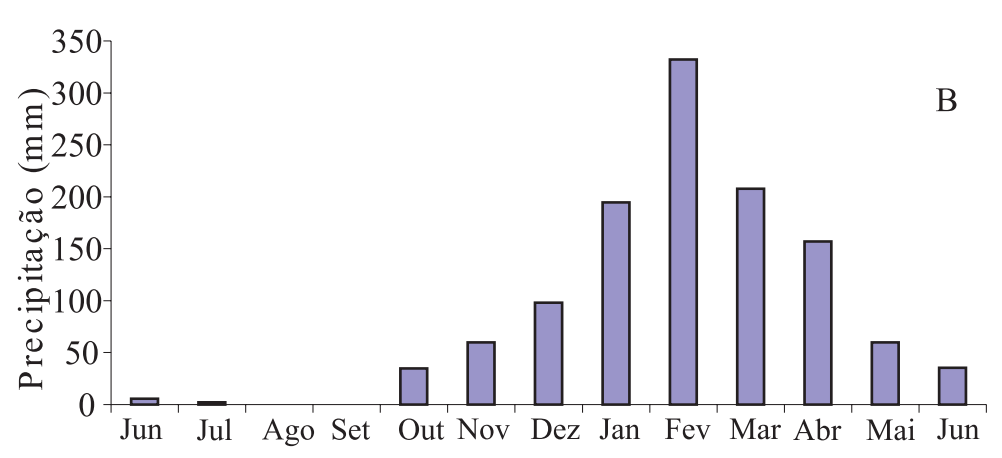

períodos secos, em geral, são desfavoráveis ao desenvolvimento de doenças nas plantas e, portanto, o que se verificou quanto às condições climáticas, pode justificar a taxa de infecção negativa que se obteve. No período de janeiro a junho de 2000, os valores de severidade foram maiores que o verificado em dezembro de 1999 (Figura 1A), porém a taxa de infecção para este período (Figura 2B) foi também negativa. Esse período foi chuvoso, podendo-se esperar uma elevação da taxa de infecção. No entanto, o agente causal é um patógeno fraco e, portanto, a expansão da doença depende da ação de outros fatores que causem injúrias, principalmente os de natureza biológica como pragas. Nos meses iniciais em que se procederam as primeiras avaliações da doença foram verificadas a ocorrência de microácaros e cochonilhas nas plantações e, nos meses chuvosos, a ausência dessas pragas. Em Palmaceae como o dendê, a ocorrência de insetos determinou o estabelecimento e o desenvolvimento de Pestalotiopsis spp nas folhas dessa planta (Araujo et al., 1991).

Observou-se que o fungo do gênero Pestalotiopsis, isolado a partir das lesões observadas no coqueiro, quando realizado o teste de patogenicidade, desenvolveu a doença unicamente nas folhas que foram feridas por ocasião da inoculação, comprovando ser um patógeno fraco; os sintomas observados em infecções naturais e nas folhas inoculadas quando da realização do teste de patogenicidade assemelharam-se àqueles descritos na literatura para a mancha foliar causada por Pestalotiopsis guepinii; a incidência da doença no campo, em todas as avaliações foi igual a 100\%; nos meses mais secos verificaram-se os maiores valores de severidade da doença e no progresso da severidade da doença as taxas de infecção foram negativas. 